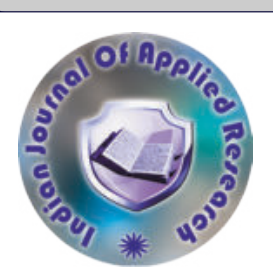

Community Medicine

\title{
ASSOCIATION OF NUMBER OF ANTENATAL CHECK-UP VISITS WITH SOCIO-DEMOGRAPHIC FACTORS AMONG PREGNANT WOMEN DELIVERING IN OBSTETRICS \& GYNAECOLOGY DEPARTMENT OF A TERTIARY CARE HOSPITAL OF JHARKHAND
}

\section{Dr. Swati Shikha \\ Dr. Abhishek Kumar*}

Assistant Professor, Department Of Community Medicine, Narayan Medical College, Sasaram, Bihar.

Assistant Professor, Department Of Community Medicine, Narayan Medical College, Sasaram, Bihar. *Corresponding Author

Dr. Vivek Kashyap Professor \& Head, Department of PSM, RIMS, Ranchi.

ABSTRACT BACKGROUND: Antenatal check- up is the routine health care of presumed healthy pregnant women without symptoms (screening), in order to diagnose diseases or complicating obstetric conditions without symptoms, and to provide information about lifestyle, pregnancy and delivery. Early registration to antenatal care is imperative for the timely diagnosis and treatment of pregnancy related morbidities. OBJECTIVES: This study aims to find the association between socio demographic factors and number of ANC visits of patients attending the Department of Obstetrics and Gynaecology, RIMS, Ranchi. METHODS: This was a cross sectional hospital based study done in Obs. \& Gynae. Department of RIMS, Ranchi for a duration of 3 months. All pregnant women admitted on the beds with odd numbers in ward during the data collection period were included. Total sample size during this period came out to be 160. Templates were generated in MS excel sheet and data analysis was done using SPSS software (version20.0). RESULTS: On analysis and applying chi-square statistics test it was found that half of the respondents had their first ANC visit within 12 weeks of pregnancy. Various sociodemographic factors like husband education, residence and occupation were significantly associated $(p<0.05)$ with number of ANC visits. It was also found that factors like motivation for ANC and type of delivery were also significantly associated $(\mathrm{p}<0.05)$ with number of ANC visits. CONCLUSIONS: It was concluded from the present study that number of ANC visits is significantly associated with socio-demographic and other factors.

\section{KEYWORDS : Antenatal Check-up, Pregnant Women, Socio-demographic Factors}

\section{INTRODUCTION}

As a part of Antenatal Care (ANC), it is very necessary to screen all the presumed healthy pregnant women without symptoms to find out the diseases or any complicating obstetric conditions without symptoms and also to provide information about lifestyle, pregnancy and delivery. ${ }^{1}$ ANC has shifted gradually from indoor care to the out-patient care at present. Early registration to antenatal care is essential for the timely diagnosis and treatment of pregnancy related complications and morbidities. ${ }^{23}$ The World Health Organization (WHO) recommends that pregnant women in developing countries should seek ANC within the first ${ }^{4}$ months of pregnancy. ${ }^{4}$ In developed countries such as the UK and the USA, the first ANC visit is recommended within the first 12 weeks of pregnancy. ${ }^{5}$ In addition, early ANC visits also enable fairly accurate calculation of the expected date of delivery, especially in women who are unsure of their last menstrual period. ${ }^{78}$

According to National Family Health Survey - 4 about $51.2 \%$ pregnant women get at least $4 \mathrm{ANC}$ in India while it is $30.3 \%$ only for Jharkhand as compared to $18.2 \%$ in NFHS-3. About $52 \%$ of mothers have their antenatal check-up in first trimester in Jharkhand as compared to the national percentage of 58.6\%. A comparison of ANC services in India \& Jharkhand according to NFHS -4 has been depicted in Figure 01. Antenatal care is an effective strategy to reduce maternal mortality. According to SRS bulletin on maternal mortality in India 2014-16, maternal mortality ratio of Bihar is 165 as compared to that of India which is 130 per lakhs live birth. ${ }^{10}$

Globally, while $85 \%$ of pregnant women access ANC with a skilled health personnel at least once, only 6 in $10(58 \%)$ receive at least 4 ANC visits."

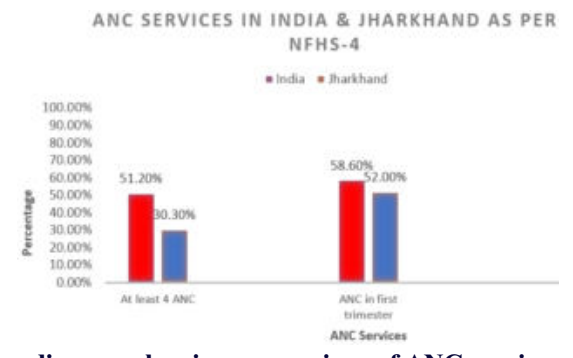

Fig 1: Bar diagram showing comparison of ANC services and their beneficiary percentage according to NFHS-4 for India \& Jharkhand
India is a developing country with most of its population living in rural areas. Antenatal check-up is important for every pregnant women during her pregnancy. Despite different government schemes for mother and child health, many pregnant women don't get the minimum required ANC. There may be some socio-demographic factors which affects the ANC visits of the pregnant women. So, this study aims to find the association between socio demographic and other factors and number of ANC visits of patients attending the Department of Obstetrics and Gynaecology, RIMS, Ranchi.

\section{METHODOLOGY}

Study Design: Hospital based cross sectional study

Study Setting: Department of obstetrics and gynaecology of RIMS, Ranchi.

Study Duration: 3 months (12 weeks).

Study Participants: All pregnant women giving their consent and admitted on the beds with odd numbers in ward during the data collection period ( 4 weeks) were included in the study.

Sample size: After completion of data collection period total number of women came out to be 160 .

Data Collection tools: A pre-tested semi structured questionnaire was used for data collection. The questionnaire included questions about socio-demographic variables and ANC visits.

Statistical Analysis: Template were generated on MS - Excel sheet with all the variables used in the questionnaire and the whole data was entered in the excel sheet. After that data analysis was done using SPSS software (version 20). p value $<0.05$ was taken to be significant. Chisquare test and binary logistic regression was applied for the analysis of data.

\section{RESULTS}

After analysis of 160 pregnant women it was found that more than half (54.4\%) pregnant women were having less than 4 ANC visits. Chisquare test was applied to find the association between number of ANC visits and socio-demographic variables and all the variables having significant association were identified. The identified variables were used to find further association using binary logistic regression analysis as shown in Table No 01. 
No. of ANC Visits of respondents $(n=160)$

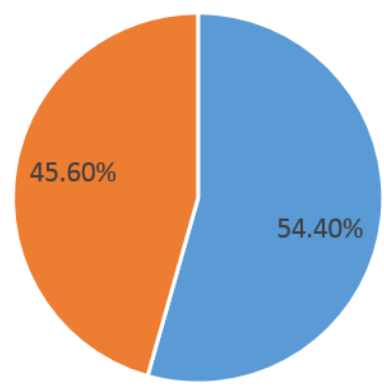

m Less than 4 - More than 4

Fig 02: Pie chart showing number of ANC visits among respondents $(\mathrm{n}=160)$

Table No 01: Association of various factors with number of ANC visits by respondents $(\mathrm{n}=160)$

\begin{tabular}{|c|c|c|c|c|c|c|}
\hline \multirow[t]{2}{*}{ Variables } & \multicolumn{6}{|c|}{ No. of ANC visits } \\
\hline & $<4$ visits & $>4$ visits & Total & $\begin{array}{l}\text { df \& p- } \\
\text { value }\end{array}$ & OR & $(95 \% \mathrm{CI})$ \\
\hline \multicolumn{7}{|l|}{ Residence } \\
\hline Rural & $43(53.1 \%)$ & $38(46.9 \%)$ & $81(100 \%)$ & $1 \& 0.002$ & 0.36 & $(0.18-0.69)$ \\
\hline Urban & $23(29.1 \%)$ & $56(70.9 \%)$ & $79(100 \%)$ & & & Ref. \\
\hline \multicolumn{7}{|c|}{ Husband Education } \\
\hline Illiterate & $5(13.5 \%)$ & $32(86.5 \%)$ & $37(100 \%)$ & $1 \& 0.001$ & 11.05 & $(3.75-32.5)$ \\
\hline Literate & $61(49.6 \%)$ & $62(50.4 \%)$ & $123(100 \%)$ & & & Ref. \\
\hline \multicolumn{7}{|l|}{ Occupation } \\
\hline Housewife & $43(44.3 \%)$ & $54(55.7 \%)$ & $97(100 \%)$ & $2 \& 0.001$ & 2.05 & $(0.878-4.81)$ \\
\hline Employed & $05(14.7 \%)$ & $29(85.3 \%)$ & $34(100 \%)$ & & 9.49 & $(2.83-31.81)$ \\
\hline \begin{tabular}{|l|} 
Small \\
Business
\end{tabular} & $18(62.1 \%)$ & $11(37.9 \%)$ & $29(100 \%)$ & & & Ref. \\
\hline \multicolumn{7}{|c|}{ Motivation for ANC } \\
\hline Self & $27(67.5 \%)$ & $13(32.5 \%)$ & $40(100 \%)$ & $2 \& 0.01$ & 0.88 & $(0.03-0.23)$ \\
\hline Sahiya & $31(45.6 \%)$ & $37(54.4 \%)$ & $68(100 \%)$ & & 0.21 & $(0.08-0.52)$ \\
\hline Others & $8(15.4 \%)$ & $44(84.6 \%)$ & $5(100 \%)$ & & & Ref. \\
\hline \multicolumn{7}{|c|}{ Time of 1st visit } \\
\hline $\begin{array}{l}\text { Before } 12 \\
\text { weeks }\end{array}$ & $36(41.4 \%)$ & $51(58.6 \%)$ & $87(100 \%)$ & $1 \& 0.97$ & 0.98 & $(0.52-1.85)$ \\
\hline \begin{tabular}{|l|} 
After 12 \\
weeks \\
\end{tabular} & $30(41.1 \%)$ & $43(58.9 \%)$ & $73(100 \%)$ & & & Ref. \\
\hline \multicolumn{7}{|c|}{ Type of delivery } \\
\hline Normal & $31(54.4 \%)$ & $26(45.6 \%)$ & $57(100 \%)$ & $1 \& 0.01$ & 0.43 & $(0.22-0.83)$ \\
\hline Caesarean & $35(34 \%)$ & $68(66 \%)$ & $103(100 \%)$ & & & Ref. \\
\hline
\end{tabular}

\section{DISCUSSIONS}

Antenatal care depends on many socio-demographic variables. It is generally seen that in developed world, women with high socioeconomic status and education, seek early and timely ANC during their pregnancy whereas in developing world, women with low socioeconomic status and education are not aware of the importance of timely ANC. ANC is an important component of pregnancy care which every women should get in adequate numbers and in timely manner. Government of India is concerned with the importance of ANC care and is running various health programs to ensure timely ANC of every pregnant women and promotion of institutional delivery also.

This was a study done to assess the socio-demographic variable which affects the number of ANC visits. On applying binary logistic regression, residence of the respondents, husband education and occupation showed significant association. In a study done by DA Adikanle et. al. it was found that after adjusting for other factors, pregnant women who had primary school education or none were more likely to book late compared to those who had secondary school education and above (OR $=2.6,95 \% \mathrm{CI}, 1.28-5.38)$. Those women who were aged less than 25 years were more likely to register late compared to those who were older $(\mathrm{OR}=8.3,95 \% \mathrm{CI}, 1.10-62.65) .{ }^{12}$

In another study done by Patel et. al. it was found that factors such as previous caesarean delivery, complications during the index pregnancy, problems in the past pregnancy and parity were not significantly associated with the time of antenatal registration. Neither the educational status of the women or their husbands was significantly associated with the time of antenatal registrationl 3 where as in this study husband education and occupation showed significant association with the number of ANC visits. A study done by M.A. Magadi et al. region of residence, the household socio-economic status, the employment status of the mother and ethnicity were observed to be important. The socioeconomic status of the household, measured by household amenities and possessions, is particularly important, influencing both the frequency and timing of antenatal care visits 14 where as in this study socio-economic status, residence and occupation is not associated with the number of ANC visits.

\section{CONCLUSIONS}

It was concluded from our study that various socio-demographic factors like husband education, residence and occupation were significantly associated $(\mathrm{p}<0.05)$ with number of ANC visits. It was also found that factors like motivation for ANC and type of delivery were also significantly associated $(\mathrm{p}<0.05)$ with number of ANC visits.

Ethical clearance: Declaration of Helsinki was followed throughout the study.

Acknowledgement: We acknowledge the contribution and guidance of our faculty members, obstetrics and gynaecology department and undergraduate students in preparation and completion of this project.

Financial support and sponsorship: Nil

Conflicts of interest: None declared

\section{REFERENCES}

1. NFOG - The Nordic Federation of Obstetrics and Gynecology [Internet]. NFOG. [cited 2020 May 30]. Available from: https://nfog.org

2. Yoong A, Chard T. The effectiveness of current antenatal care. Prog Obstet Gynaecol. 1996;12:3-18.

3. Okunlola MA, Ayinde OA, Owonikoko KM, Omigbodun AO. Factors influencing gestational age at antenatal booking at the University College Hospital, Ibadan, Nigeria. J Obstet Gynaecol. 2006 Jan 1;26(3):195-7.

4. Carroli G, Villar J, Piaggio G, Khan-Neelofur D, Gülmezoglu M, Mugford M, et al. WHO systematic review of randomised controlled trials of routine antenatal care. Lancet Lond Engl. 2001 May 19;357(9268):1565-70.

5. National Collaborating Centre for Women's and Children's Health (UK). Antenatal Care: Routine Care for the Healthy Pregnant Woman [Internet]. London: RCOG Press; 2008 [cited 2020 May 30]. (National Institute for Health and Clinical Excellence: 2008 [cited 2020 May 30]. (National Institute for Health and Clinical Excel
Guidance). Available from: http://www.ncbi.nlm.nih.gov/books/NBK51886/

6. American Academy of Pediatrics, American College of Obstetricians and Gynecologists, editors. Guidelines for perinatal care. 7th ed. Elk Grove Village, IL $\square$ : Washington, DC: American Academy of Pediatrics $\square$; American College of Obstetricians and Gynecologists; 2012.580 p.

7. National Collaborating Centre for Women's and Children's Health (UK). Antenatal Care: Routine Care for the Healthy Pregnant Woman [Internet]. London: RCOG Press; 2008 [cited 2020 May 30]. (National Institute for Health and Clinical Excellence: Guidance). Available from: http://www.ncbi.nlm.nih.gov/books/NBK51886/

8. WHO antenatal care randomized trial $\square$ : manual for the implementation of the new model [Internet]. [cited 2020 May 30]. Available from: https://apps.who.int/iris/handle/ $10665 / 42513$

9. India.pdf [Internet]. [cited 2020 May 30]. Available from: http://rchiips.org/NFHS/pdf/ NFHS4/India.pdf

10. Sample Registration Bulletin.pdf.

11. Antenatal care [Internet]. UNICEF DATA. [cited 2020 May 30]. Available from https://data.unicef.org/topic/maternal-health/antenatal-care/

12. 2008-1-4.pdf[Internet]. [cited 2020 May 30]. Available from: http://cogprints.org/6084 1/2008-1-4.pdf

13. Patel PB, Rupani MP, Patel SS. Antenatal care registration and predicting factors of late registration among pregnant women. Trop Doct. 2013 Jan 1;43(1):9-12.

14. Magadi MA, Madise NJ, Rodrigues RN. Frequency and timing of antenatal care in Kenya: explaining the variations between women of different communities. Soc Sci Kenya: explaining the variations betwe
Med 1982.2000 Aug;51(4):551-61. 